\title{
Preliminary accident analysis of ex-vessel LOCA for the European DEMO
} HCPB blanket concept

\section{Xue Zhou Jin}

Evolution scheme of the ex-vessel LOCA

Modelling using MELCOR1.8.6 for fusion
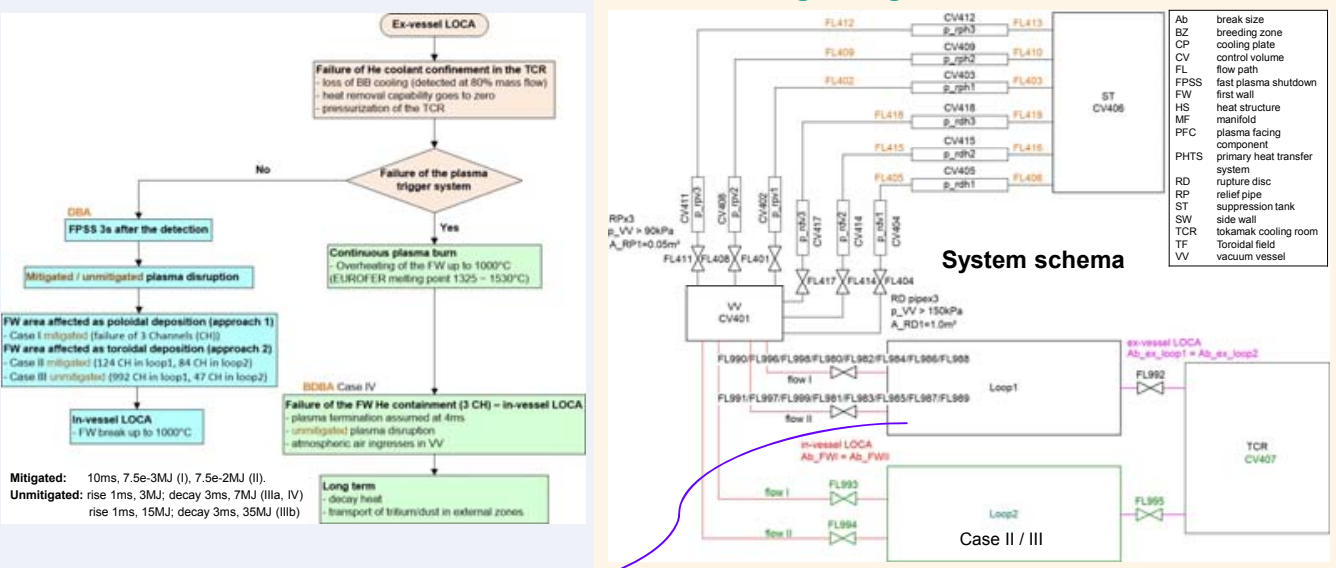

$\underline{\text { Loop1 }}$

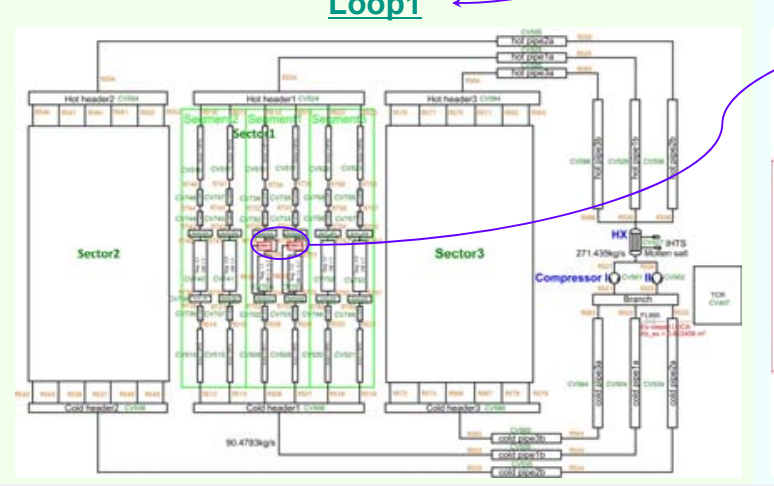

Scenarios \& time evolution in transient

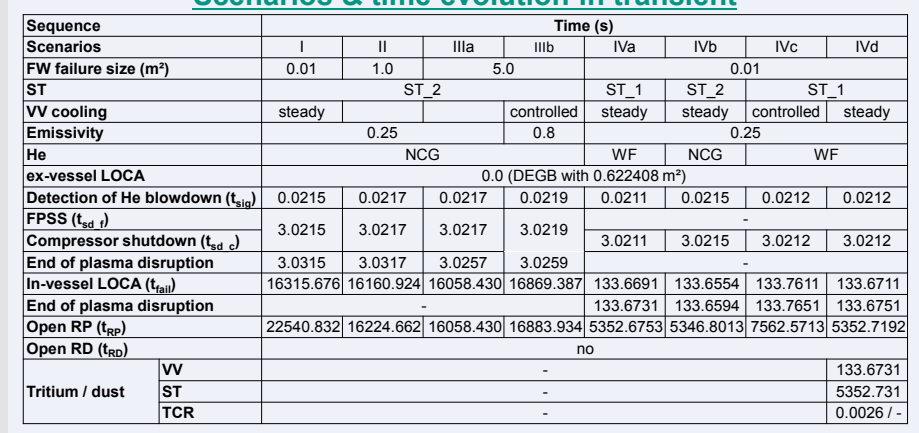

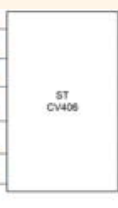

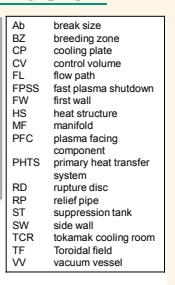

System schema

Reference design

- DEMO baseline 2015 (18TF)

- HCPB2016 vs. HCPB2015V3

$\square$ Double-caps at top and bottom: 42 cooling channels / CP, cross section $5 \mathrm{~mm} \times 5 \mathrm{~mm}$

$\square$ BZ: 42 cooling channels / CP, cross section $5 \mathrm{~mm} \times 3 \mathrm{~mm}, 60 \mathrm{CPs}$

- PHTS for HCPB2015V3: inlet piping through the lower ports

- Parameters for the VV, ST and TCR:

\begin{tabular}{|l|c|c|c|}
\hline \multicolumn{1}{|c|}{ Item } & $\mathbf{V}$ [ $^{\mathbf{3}}{ }^{\mathbf{3}}$ & $\left.\mathbf{T}{ }^{\circ} \mathbf{C}\right]$ & $\mathbf{p}[\mathbf{k P a}]$ \\
\hline VV & 2502 & 300 & 0.1 \\
\hline ST_1 (dry) & 50000 & 30 & 4.5 \\
\hline ST_2 (wet, air/water) & $49900 / 100$ & 30 & 4.5 \\
\hline 1xRP (3x) & 2.0 & 30 & 4.5 \\
\hline 1xRD (3x) & 40.0 & 30 & 4.5 \\
\hline TCR & 60700 & 30 & 98.0 \\
\hline
\end{tabular}

$\longrightarrow$ OB4

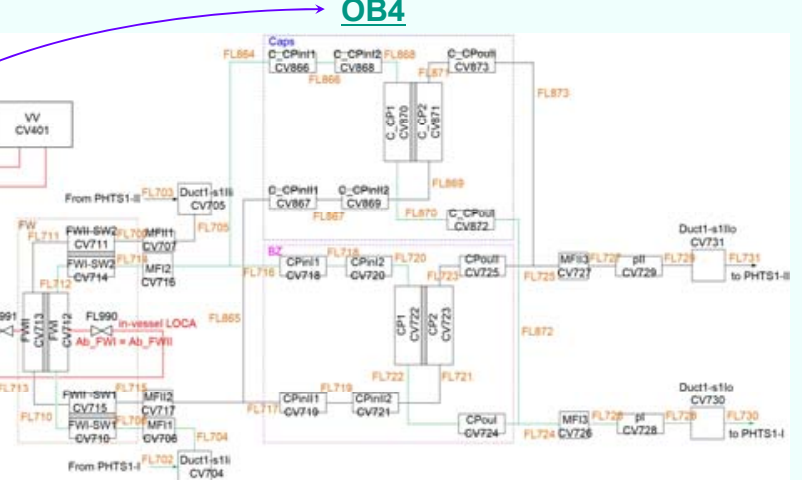

\section{CaselVo}

- Source terms

o W-dust: $25 \mathrm{~kg} \& 5 \mathrm{~kg}$ at disruption

o Tritium: $351 \sim 2450 \mathrm{~g}$ in PFC, $106.76 \mathrm{~g}$ in BMs, $0.64 \mathrm{~g} / \mathrm{loop}$

- Results at $t_{\text {end }}$ (volume \& HS) o Dust: $29.9644 \mathrm{~kg}$ in the VV, 4.78744e-3kg in the ST, not in the TCR.

o Tritium: $2.4477 \mathrm{~kg}$ in the VV $5.1358 \mathrm{e}-4 \mathrm{~kg}$ in the ST, $1.6135 \mathrm{e}-2 \mathrm{~kg}$ in the TCR.

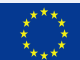

Conclusion

- He inventory of two loops of 3.1696e $3 \mathrm{~kg}$ has impact on the pressurization of the TCR, the VV and the ST. A pressure peak in the TCR of $1.64465 \mathrm{e} 5 \mathrm{~Pa}$ is $25.81 \%$ higher than it from one loop.

- In-vessel LOCA at $\sim 134 \mathrm{~s}$ due to the BDBA; it is postponed to $\sim 4.46 \mathrm{~h}$ in the DBA.

- Remove the excessive power in the $\mathrm{VV}$ during the in-vessel LOCA, $\mathrm{T}_{\mathrm{Vv}}$ can retain at $T_{O B}$ in, and the in-vessel LOCA is delayed.

- The $\mathrm{VV}$ pressure increased to the system equilibrium level is less than $\mathrm{P}_{\mathrm{V} \_} \mathrm{RD}$, thus the RD is closed all the time.

- Temperature can be reduced effectively in the wet ST.

- For the small break size, the most dust and tritium stay in the VV. Dust is not transported to the TCR.

- Next steps: detailed VV model for effective heat removal; in-vessel LOCA for large failure size in two loops; and source terms transport for the max. releases.

Transient
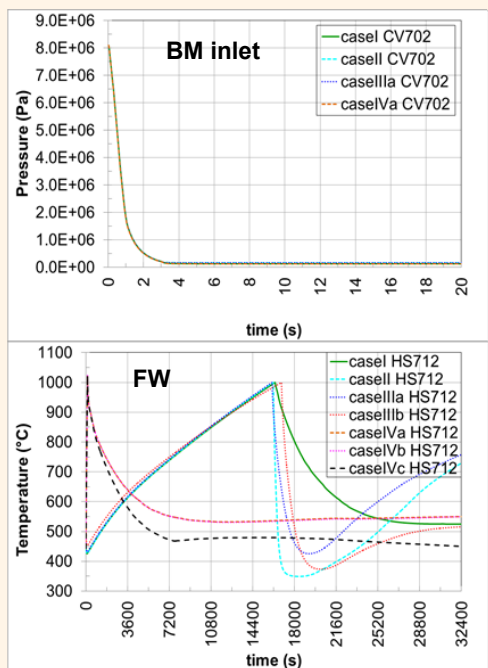

KIT - University of the State of Baden-Wuerttemberg and National Research Center of the Helmholtz Association
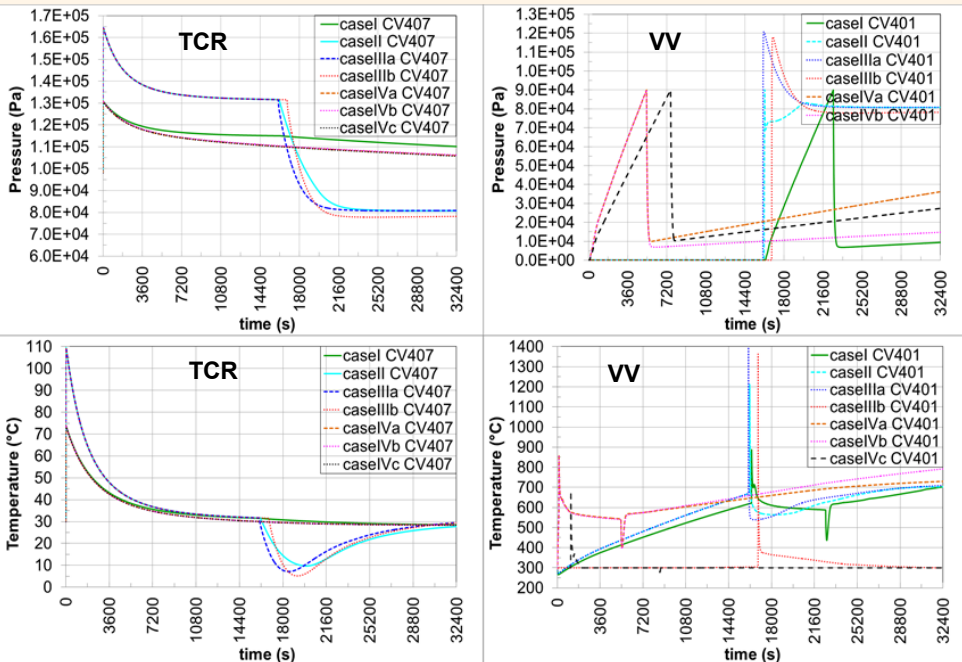
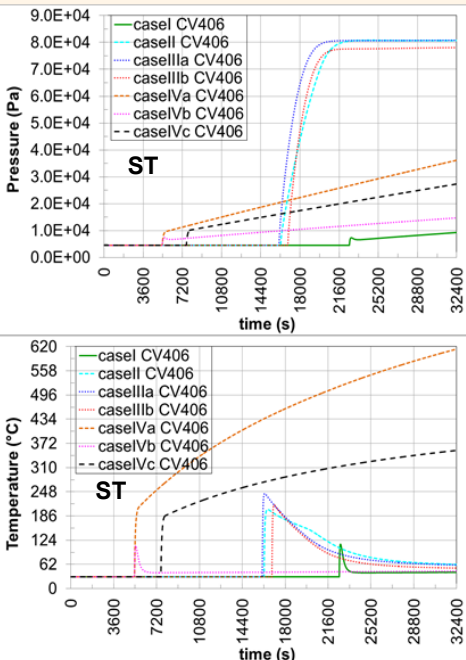